\title{
Sweet Money: Cultural and Economic Value in Trollope's Autobiography
}

\author{
Silvana Colella
}

University of Macerata (Italy)

\section{Introduction}

Trollope's Autobiography is a good example of literary capitalism. The hero of this narrative very closely resembles the rational agent of economic discourse. He optimizes the use of his time by opting for multiple job-holding and increases his output by responding to financial incentives. He proves to be a reliable, steady supplier of fresh merchandize in an expanding market of insatiable readers, and a tough negotiator determined to pursue his self-interest. In twenty years he accumulates quite a fortune, but does not fall prey to hoarding or oversaving. He enjoys consumption (the small luxuries of life: hunting and good wine) almost as much as he enjoys production. For him the market is a fact of life. No wonder that the early reviewers of the Autobiography feared that Trollope had "brutalised" the literary ideal. ${ }^{1}$ Literature was a commodity, but it had to be priceless: by attaching a price tag to the products of his imagination, Trollope had exposed the primacy of exchange value.

This picture of the author as a rational maximiser of his own utility, however, is almost too good-or too bad-to be believable. Critics have often noticed that "the Trollope who speaks to us in the Autobiography" is disconcertingly different from the implied author of his novels (Allen 4). The latter is "at ease in genteel society" and a "reliable guide to its practices and values" (Allen 3-4). The former is at ease in the marketplace and an able trader in literary goods. Since the narrator of An Autobiography seems so unperturbed by vulgar materialism, some critics have a tendency not to take him too seriously (Allen 6). In this essay I take him at face value. How does this narrator describe the market in which he operated? As a producer, does he feel equally confident in both domestic and international markets? How does he tackle the issue of overproduction? How does he deal with the tension between literary and economic value? Finally, what is the relationship between Trollope the tradesman and Trollope the theorist? 
An Autobiography focuses on the trajectory of Trollope's career rather than on the record of his "inner life" (XX: 365). At different stages, Trollope explains his working method, claiming, among other things, that he always began his daily task "by reading the work of the day before" (XV: 272). He recommends this strategy to aspiring writers: "by reading what he has last written, just before he recommences his task, the writer will catch the tone and spirit of what he is than saying, and will avoid the fault of seeming to be unlike himself" (XV: 272). This scheme of work seems devised to emphasise linearity and consecutiveness. The narrative thus produced will appear as an uninterrupted continuum of successive verbal acts, linked to one another by the very logic of linear consecutiveness. This logic is also at work in the Autobiography even when the chronological narrative gives way to comments, theories and explanations that are offered as retrospective insights on the literary profession. ${ }^{2}$ Trollope's comments-his famous pronouncements on the business of writing, the art of characterization and the role of the market-have often been read as general statements that are interesting in themselves regardless of their position within the linear development of his autobiographical narrative. My contention is that such position matters.

Trollope's definition of the novelist as a "preacher of sermons" is a good case in point. This definition crops up soon after Trollope has completed his detailed account of how one publisher-Smith in this case-discouraged him from writing another Irish story and "suggested the Church as though it were my peculiar subject. He wanted an English tale, on English life, with a clerical flavour. On these orders I went to work, and framed what I suppose I might call the plot of Framley Parsonage" (VIII: 142). In the autobiographical reconstruction, the "clerical flavour" demanded or "ordered" by the market becomes the distinguishing feature of the novelist himself: "I have ever thought of myself as a preacher of sermons, and my pulpit as one which I could make both salutary and agreeable to my audience" (VIII: 146). The religious metaphor connects the present and the past. In the linear development of narrative discourse, Trollope's definition of the novelist as preacher is contiguous to the episode he has just narrated. This episode centres on the transaction between a publisher "at the top of the tree" and an author "still at the bottom" (VIII: 141). The former dictates the terms and suggests the topic, while the latter executes his "orders". But the author who writes his own autobiography is now in a position to revise this transaction and to symbolically re-appropriate the "clerical flavour". Thus the external "order" becomes a free choice. If the church was not Trollope's "peculiar subject", years later it is constructed metaphorically as the peculiar province of the novelist as preacher. Trollope's autobiographical self simultaneously acknowledges the pressures of the market and denies them, albeit indirectly. In this respect, linear successiveness is indeed a meaningful strategy rather than an "entrapping" imperative. ${ }^{3}$ There are other moments in $A n$ Autobiography when Trollope's general truths or theories seem to be called forth by the wish to rationalize the primary text of life. My reading focuses on these moments and on the interaction between autobiographical fragments and authorial comments, resituating those comments in their specific textual location. Their position within the linear succession of verbal acts that constitutes the text of An Autobiography is crucial 
in order to understand to what purpose Trollope mobilizes, in such a conspicuous way, the language of trade and the business ideal.

"Retrospective narrative" — writes Rosemarie Bodenheimer- "is built on an oscillating arrow of time. It selects its past and suffuses it with the language and consciousness of the present" (215). All autobiographical narratives are written backwards from the hindsight of their ending (Davis 81). Trollope's is no exception. His consciousness of the present affects the way in which the narrative moves forward, reconstructing the past and making sense of a professional life, "while that life is happening". ${ }^{4}$ For this very reason, linearity and formal successiveness become meaningful ways of accounting for the past, of explaining and rationalizing the primary text of life. Trollope wrote his Autobiography at a time when the value of his literary stock was at a low point. ${ }^{5}$ Not surprisingly, the question of value - the tension between literary value and economic value-is a recurrent concern in this text. In the mid 1870s he was also a member of the Royal Commission on International Copyright. The debate on international copyright, as Claire Pettit has demonstrated, pivoted on the issue of control. English authors feared that, in an open, global marketplace, they had little power to control the dissemination of their works (Pettit 280). The piracy of British books by North American publishers fuelled their anxieties. It is with reference to this controversial scenario that I reconsider the model of control Trollope meticulously elaborates (and even promotes) in An Autobiography. Despite Trollope's confidence, the marketplace in which he operated was indeed dangerously open and unpredictable.

\section{The Author as Producer}

If the market is defined as the arena where supply and demand meet, then the market Trollope describes in the first volume of the Autobiography is characterized by randomness, chance, uncertainty and irrational haste. In the years preceding his popularity and commercial success, Trollope's dealings with different publishers are remarkable for his determined pursuit of self-interest and for the "furious haste" (VI: 117) with which he concludes deals on the sale of his work. The story of how Trollope sold the manuscript of The Three Clerks is well-known. Since Mr. Longman refused to agree on a lump sum, Trollope- "the most nomadic of the great Victorian novelists" (Sutherland, Victorian Novelists 136) — took his book to Hurst \& Blackett. But the "peccant publisher" failed to turn up. Having little time to dispose of his manuscript, Trollope decided to try his luck elsewhere and in the same afternoon concluded his deal with

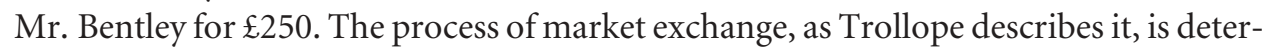
mined by a mixture of chance, hurriedness and sheer tenacity. There is no planning and no certainty as to the final outcome. Armed with a strong determination, Trollope gauges different buyers and fortuitously stumbles across the right one.

The sale of the copyright of Dr. Thorne is narrated along the same lines. Before leaving for Egypt, Trollope rushes to London from Dublin and demands $\mathfrak{E} 400$ from Mr. Bentley. The publisher initially accepts, but then reconsiders and offers $\mathfrak{E} 300$. Trollope stubbornly refuses: "I was intent upon the larger sum-he explains—and in furious haste I rushed to Chapman \& Hall in Piccadilly and said what I had to say to 
Mr. Edward Chapman in a quick torrent of words" (VI: 117). The "quick torrent of words" is effective and the transaction is concluded. But Trollope's retrospective account of this sale emphasises a lingering element of doubt as to whether this rapid and aggressive exchange counted as a proper sale:

Looking at me as he might have done at a highway robber who had stopped him on Houn-
slow Heath, he said that he supposed he might as well do as I desired. I considered this to
be a sale, and it was a sale. I remember that he held a poker in his hand all the time that I
was with him;--but in truth, even though he had declined to buy the book, there would
have been no danger. (VI: 117)

The most problematic issue in this and other similar episodes is what Trollope terms the "outside value of the novel" (VI: 117): why is $\mathfrak{E} 400$ a good price, and not $\mathfrak{E} 300$ or $\mathfrak{E} 500$ ? The process of value formation, in this instance, seems rather arbitrary, just as the transaction itself seems the unlikely result of chance and haste. However, in the ensuing pages this arbitrariness is soon rationalized when Trollope for the first time explains his "system of task-work" and his belief in "quantity":

In the bargains I have made with publishers, I have-not, of course, with their knowledge, but in my own mind-undertaken always to supply them with so many words, and I have never put a book out of hand short of the number by a single word. [...] I have prided myself on completing my work exactly within the proposed dimensions. But I have prided myself especially on completing it within the proposed time,- - and I have always done so. (VII: 119)

Whereas the market exchanges Trollope has just described are beset by uncertainty and randomness, the system of task-work he now promotes is, on the contrary, fully rational, efficient and well-organized ("labour-he claims-should never be allowed to become spasmodic", VII: 118). The technique of word count (the emphasis on quantity) gives the impression that the value of a novel may not be entirely arbitrary. Trollope mobilizes the business ideal—with its insistence on regularity, punctuality and standardized routines-at a specific juncture in the narrative of his professional life: when he needs to reposition himself as a rational producer vis-à-vis a market dominated by forces that are beyond his control. ${ }^{6}$ That Trollope chose to reveal his working method soon after recounting his negotiations with the publishers cannot be entirely coincidental. The bureaucratization of the work of writing, for which Trollope is notorious, is not a generic mimesis of market values but a specific response to the irrationality of market exchanges, as they are depicted in the Autobiography. Chapter VII constructs an image of the writer as rational and efficient producer that stands in open contrast to the image of the writer who, in chapter VI, was selling his manuscripts in a "furious haste" and improvising on important financial matters. It is the first image that Trollope wants to promote. The regular and self-disciplined producer of novels controls the value of his goods by controlling and standardizing quantity — so many words per page, so many pages in a volume, so many hours of work each day-thus fully earning the right to determine the correct price of his merchandize. In the complicated ideological agenda of Trollope's autobiography, proving his credentials as an honest literary tradesman is indeed relevant. In this context, arbitrary decisions on price ought to be ruled out. 
"Among Victorian authors"—writes Robert Aguirre- "Trollope is by far the most blunt about business matters" (57). Trollope is particularly eloquent on the subject of money-making: "the love of money" he claims is a "distinctive characteristic of humanity" (VI: 105) and authors have a right to expect pecuniary returns. In chapter VI, just before recounting his hurried negotiations for the sale of The Three Clerks, Trollope expounds his "theory" of money as the legitimate "first object" of artists and authors. There is no reason why authors should not follow the example of barristers, clergymen, doctors, butchers and bankers who "without disgrace follow the bent of human nature, and endeavour to fill their bellies and clothe their backs, and also those of their wives and children, as comfortably as they can by the exercise of their abilities and their crafts" (VI: 105). Trollope parades professionals and tradesmen alongside authors, painters and composers, thus deflating the traditional view of the artistic vocation as immune to economic self-interest. Moreover, by grouping tradesmen (butchers) and professionals (barristers) in one broad class of self-interested agents, Trollope sweepingly rewrites the terms of the debate on professionalism that was raging at that time. In the debate on the "dignity" of the legal profession, for instance, lawyers were keen to present themselves as offering a service to the community rather than practicing a trade from which they expected to profit (Searle 107). ${ }^{7}$ Trollope, on the contrary, insists that "the more a man earns the more useful he is to his fellow-men" (VI: 106), thus conflating disinterestedness and self-interest, social usefulness and instrumental rationality in one single stroke. It is hard to imagine a more direct and unembarrassed legitimization of the entrepreneurial ideal. It is also hard to reconcile this claim with Trollope's ideals of gentility and gentlemanliness, promoted in his novels.

Why does An Autobiography tilt the balance so very conspicuously in favour of trade? Critics have often suggested that Trollope's "materialism" is a "self-parody". We should therefore "discount some of what he says as humorous exaggeration or wilful misrepresentation" (Allan 13). For James Kincaid, An Autobiography is a "mercantile comedy" in which the final stage of prosperity is reached too early for this narrative to appear consistent (348). Whether self-mocking or comic, Trollope's appeal to the language of trade is a rhetorical strategy that serves more than one purpose. By marshalling the entrepreneurial ideal, Trollope assumes the model of free agency and self-determination intrinsic to that ideal. Thus, his autobiographical persona is constructed as a rational agent who does not passively acquiesce to the demands of the market. Rather he appears determined to control the process of market exchange and to benefit from it. The chances of the market are indeed unpredictable, as the Trollope who was writing his own autobiography knew all too well. Instead, the hero of his narrative appears in command. By controlling production, he determines the price of his goods. He writes for the market but is not subservient to it. The fulcrum of this model is the self-determined "I". For this "I" to appear convincingly in control of his destiny, the business ideal has to be continuously reinforced. In An Autobiography Trollope mobilizes this ideal so as to emphasise the free agency of the author and to minimize the pressures of the market. If the gentleman status is appealing because it promises freedom from the pressing needs of money-making, the Trollopian version 
of the business ideal is appealing because it turns the need to make money into an assertion of freedom and control.

This freedom is a retrospective fiction, a dream of control, at least partly. As David Throsby argues, authors supply a dual market (104): the market where commodities are bought and sold and the market where creative ideas circulate and are praised or criticized according to a standard of value that is far more elusive than the unit of account used in monetary transactions. The price of a novel depends on the interconnections between cultural and market value. The author who achieves a high degree of critical acclaim and popularity commands a higher price on the market. The "capital of consecration", as Bourdieu explains, is cashed in as economic capital (75). ${ }^{8}$ The tension between cultural and economic value is a matter of concern for Trollope. His autobiographical account focuses on market price and the commodity form, but the question of value is not just resolved by totting up profits or boasting quantity. What demands further attention is precisely Trollope's unbalanced commodification of literary goods. This commodification has appeared debatable for ideological reasons. But it is also questionable from an economic point of view.

To what extent are literary goods comparable to standard goods? According to economic theory, literary and artistic goods are not homogenous products. Their features are unique and the degree of substitutability between different literary works is typically much lower than between standard goods, such as candles. Their value is therefore much more difficult to define. Trollope is aware that the novelist's predicament is significantly different from that of a "seller of cloth": "No doubt the author or the artist may have a difficulty which will not occur to the seller of cloth, in settling within himself what is good work and what bad—when labour enough has been given, and when the task has been scamped" (VI: 108). Value remains an elusive and tricky issue despite Trollope's rhetorical appropriation of the language of trade. The deployment of this language tends to efface the difference between literary goods and standard goods. Although both types of goods are commodities, their economic value is not determined in the same way. Trollope's labour theory of value, expounded in chapter VI, gives the impression that the determination of value is a matter of word-counting and hours of labour devoted to the fabrication of a novel. The unpredictable mechanisms of cultural consecration that exert such a strong influence on the market value of literary goods are thus set aside, while the author reclaims for himself the role of rational producer who controls the value of his own merchandize.

\section{Cultural Value and Market Price}

The labour theory of value works very well as a retrospective justification of how the author came to demand a certain price, a fair price-say $\mathfrak{E} 400$ - for his intellectual labour. But it proves inadequate when cultural value, all of a sudden, takes precedence over economic value. The cultural value of The West Indies and the Spanish Main (1859), for instance, far exceeded its economic value (Trollope received $\mathfrak{2} 250$ for the copyright) and was determined by a series of articles in the Times newspaper that, as Trollope admits, "made the fortune of the book" (VII: 130) and raised his position as 
an author. The crucial element in this case is the role played by chance in boosting Trollope's reputation-a role he is quick to deny by claiming that he feels "under no obligation" to the writer of those articles and that this volume is his "best book" (VII: 130). The determination of value has shifted. It is with reference to this episode that Trollope theorizes the distinction between a "confidence in fact" and a "confidence in vision" conferring upon the reader the power to decide which model he prefers.

There is a confidence in fact and a confidence in vision. The one man tells you accurately what has been. The other suggests to you what may, or perhaps what must have been, or what ought to have been. The former requires simple faith. The latter calls upon you to judge for yourself, and form your own conclusions. [...] Either may be false,-wilfully false; as also may either be steadfastly true. As to that, the reader must judge for himself. (VII: 129-30)

In this section Trollope is trying to explain and rationalize the critical acclaim of a travel book that, as he honestly admits, was written without any preparation, without taking "a single note" (VII: 129), and was therefore most likely to be inaccurate. The "confidence in vision" he now proposes as a model of evaluation designates the reader as the ultimate adjudicator. The reader, Trollope concludes, "must judge for himself", just as the anonymous reader of the Times had indeed freely chosen to place his confidence in Trollope's "vision" and to value his writing accordingly. If Trollope's success is to be represented in the Autobiography as fully earned, then the sudden increase in his capital of recognition that occurs with the publication of The West Indies and the Spanish Main must somehow be accounted for-the symbolic profit he reaps must not appear as an undeserved bonus, or a free gift. The theory of confidence Trollope proposes allows for a more elusive and elastic process of value formation whereby the reader, and not the author, becomes the symbolic price maker. The reader's confidence in the literary worth of this book is then translated into economic terms: $\mathfrak{E} 600$ is now the equilibrium price Trollope feels confident to demand for his next novel.

I am aware that by that criticism I was much raised in my position as an author. Whether such lifting up by such means is good or bad for literature is a question which I hope to discuss in a future chapter. But the result was immediate to me, for I at once went to Chapman \& Hall and successfully demanded $£ 600$ for my next novel. (VII: 130-31)

Although the way in which this episode is reframed suggests that literary goods are indeed different from standard goods, Trollope continues to fall back on the quantityof-labour model. In chapter IX, the sum of $\mathfrak{E} 600$ is indicated as the standard market price corresponding to the "quantity contained in an ordinary novel volume" (161). A

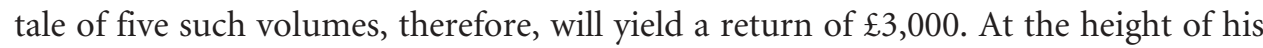
popularity, the profits Trollope makes are still presented as proportional to the number of pages he produces. "Having said so much"—Trollope concludes— "I need no further specify the prices as I mention the books as they were written" (IX: 161). This assertion sounds as a final, definitive statement. Readers may rest assured that the length of his novels - and he produced some prodigiously long tales—is the quantifiable standard by which his profits are determined and justified. However, this parameter does not account for the very different returns Trollope made on the sale of 
Framley Parsonage, issued in sixteen parts, and The Small House at Allington, only a quarter longer (twenty parts): Smith Elder paid $\mathfrak{£} 1,000$ for the former and $\mathfrak{k} 3,000$ for the latter. Literary goods are not homogenous products and for this very reason their value cannot be quantified and standardized as can the value of candles. The central chapters of An Autobiography demonstrate that the issue of price is not settled once and for all by invoking a quantitative standard. In these chapters Trollope justifies his soaring profits by appealing to a different "regime of value": the market is now willing to reward innovation and creativity, just as it was willing to reward industriousness, hard work and punctuality in the previous chapters. ${ }^{9}$

Chapter X addresses one of the thorniest issues Trollope had to tackle in his experience as a writer: the question of overproduction. In the expanding market for fiction of the 1860s, the fear of overproduction was simply not an issue from an economic point of view. The market was indeed ready to absorb buoyant supply of new titles. Alexis Weedon claims that "from the 1830s to the 1870 s there was a 'book hunger', and only in the 1880s did production begin to catch up with demand" (157). The market for literature, in particular, "required a higher number of fresh titles, in contrast to the market for religious works, mathematics, and languages where the range of choice is less of an issue than the number of copies" (92).

However, as David Skilton has shown, overproduction was a recurrent concern of Trollope's critics who grew quickly suspicious of the sheer amount of volumes Trollope churned out between 1862 and 1869, with startling regularity. As a result, he was frequently accused of "hasty writing and superficial mechanical work" (Skilton 31). Trollope's indirect response to these charges, in the Autobiography, is well-known: "I believe that the work which has been done quickest has been done the best" (X: 174). His defence of "rapid writing" as "the most effective and by no means the most inaccurate" (X: 178) model of composition matches, on the supply side, the increasing demand for fiction that he himself had experienced in his dealings with different publishers. In these years, Trollope encounters no difficulty selling his wares. Quantity can easily be absorbed in an expanding market.

But quality is a slightly different matter. It is probably no coincidence that Trollope expounds his theory of characterization, the core of his system of aesthetic evaluations, in chapter X of the Autobiography in which he also deals with overproduction. ${ }^{10}$ He appears uneasy that quantity might backfire: "I admit that I crowded my wares into the market too quickly, because the reading world could not want such a quantity of matter from the hands of one author in so short a space of time" (X: 173). The interesting connection, in this case, is between Trollope's fear of diminishing utility (consumers might not want to buy too many units of the same article), and the aesthetic law of increasing returns he conjures up when he describes the "string of characters" (X: 184) carried on from one story to another as the "best work" of his life.

In talking about the novels of this period, Trollope seems determined to rewrite quantity as quality. The theory of "rapid writing" serves this purpose. But the most effective value-switching moment, which allows commodified quantity to be re-singularised as aesthetic value, is Trollope's heart-felt vindication of his characters as "real personages", 
growing and changing with time, reappearing in story after story, and therefore connecting in one wide "canvas" all the different novels he has produced: ${ }^{11}$

To carry out my scheme I have had to spread my picture over so wide a canvas that I cannot expect that any lover of such art should trouble himself to look at it as a whole. Who will read Can You Forgive Her? Phineas Finn, Phineas Redux, and The Prime Minister consecutively, in order that he may understand the characters of the Duke of Omnium, of Plantagenet Palliser, and Lady Glencora? Who will ever know that they should be so read? [...] I look upon this string of characters,-—carried sometimes into other novels than those just named,- -as the best work of my life. (X: 184)

The ideal reader Trollope's rhetorical questions imply is capable of appreciating the increasing returns, in terms of aesthetic pleasure, that reading those novels consecutively is sure to yield. If taken separately, these novels may appear overabundant. But if considered as a whole, they provide just the right amount of space necessary for the successful completion of Trollope's scheme. The Autobiography is there to teach future sceptical readers that quantity may be the necessary complement of quality just as economic value may indeed coincide with aesthetic and literary value. Even a cursory look at the final catalogue, in which Trollope itemises all his books and earnings, will confirm that the novels yielding the highest economic profits are those featuring the "string of characters" he considers most memorable. ${ }^{12}$ Since the creation of "real personages" is, according to him, the "ultimate standard for evaluating any novel" (Kendrick 21), in the central chapters of the Autobiography a perfect balance is established between exchange value and aesthetic value. The former is so high-in the region of $\mathfrak{E 3 0 0 0}$ for each new novel—that the latter has to be raised accordingly.

Nothing short of a theory will suffice to do that. I agree with Kendrick that Trollope's aesthetic theory of realism is interesting in itself. But in the narrative economy of the Autobiography, this theory also functions as an ad hoc construction that allows Trollope to justify his profits and his addictive productivity by invoking a different regime of value in which the author as creator, rather than the author as producer, becomes prominent. According to this theory, the overproduction critics are inclined to condemn is defended as the creation of one single "canvas", one consecutive tale of different human lives. The author who abnormally increases his output to catch up with demand is thereby credited as the unique creator of "speaking, moving, living human creatures" (XII: 232) who need space and time to grow to full proportions. Although the belief in characters as living people was "a pervasive demand of midVictorian criticism" (Kendrick 24), the intensity with which Trollope subscribes to this belief contributes to increasing the cultural value of his literary goods. These commodities are unique, and therefore highly priced.

Chapter $\mathrm{X}$ is relevant in this context. It starts off with a description of profitable overworking - "Instead of writing eight pages a day, I have written sixteen; instead of working five days a week, I have worked seven. I have trebled my usual average [...]" (X: 175)_and smoothly glides into the more romantic scenario of creative conception.

At such times I have been able to imbue myself thoroughly with the characters I have had in hand. I have wandered alone among rocks and woods, crying at their grief, laughing at their absurdity, and thoroughly enjoying their joy. I have been impregnated with my own 
creations, till it has been my only excitement to sit with the pen in my hand, and drive my team before me at as quick a pace as I could make them travel. (X: 176)

In this chapter Trollope discusses his novels with reference to two different regimes of value. Novels are both commodities and singularised objects. They have a market price and a cultural 'price'. While the first is settled, the latter is a matter of some contention. The theory of characterization developed in this section and Trollope's personal reassessment of his own characters tend to raise their cultural value. Whether or not he is thus trying to rationalize his "taste for more" (XX: 366), ${ }^{13}$ it is significant that he singles out as his best creations precisely the characters that appear in the novels yielding the most formidable profits.

Given Trollope's “secretarial exactitude" (Sutherland, Victorian Fiction 132) in counting his pounds, shillings and pence, the earnings he declares in such a matter-offact way have appeared so self-evident—-they are numbers, after all—as to require no further questioning. The final catalogue with which he concludes his autobiography has often been read as a simple "inventory of productivity" (Aguirre 574), a little eccentric maybe, for someone whose business is the imagination, but not terribly relevant. However, in the Autobiography Trollope is not simply totting up profits, he is also making sense of them. Profits, whether high or low, are indeed explained and accounted for in many ways. Regularity, punctuality and industriousness are the virtues that lead to Trollope's well-deserved gains, in line with the Victorian business ethic. At a very general level, this is the story of self-help the Autobiography narrates. At a more specific level, Trollope's aesthetic pronouncements (some of them, at least) can also be read as justifications of economic profits. Why should Trollope wish to justify the money he makes, since he does not appear embarrassed by the profit motif? The obvious answer is honesty, or the wish to present his profits as well-earned. The less obvious, but still plausible answer is the wish to defend the cultural value and uniqueness of his creations by showing that the market sets a high price on them. In this respect, the Autobiography is a little more subtle than a "mercantile comedy" whose hero poses as a vulgar tradesman.

\section{The Author as Creator}

"Brains that are unbought"-Trollope declares— "will never serve the public much" (VI: 107). The selling of brains that allows Trollope to serve the public takes many shapes in the Autobiography. It is a straightforward market transaction, as in his restless commerce with different publishers, but also a more intangible service rendered to a variety of readers in a vast, multinational market. This service is connected to an image of the individual as innovative creator who benefits the community by capitalizing on his natural talents. Trollope refines this image throughout the Autobiography, often with reference to his role as public servant at the General Post Office. What could be less creative than a job at the Post Office? Yet Trollope never fails to emphasise his role as innovator within this large organization. In this context, it is not dull adhesion to the work ethic that allows him to rise, but a combination of good ideas, personal enjoyment and dedication to the job. In Ireland, his love of horse-riding is in 
fact instrumental in determining great improvements in the postal system: "I did my business"-Trollope remembers— "after a fashion in which no other official man has worked, at least for many years. I went almost everywhere on horseback" (V: 88). His descriptions of how he sometimes came to surprise "some small country postmaster" (V: 90) by appearing at nine in the morning fully clad in his hunting outfit are indeed a good deal more dashing and romantic than his writing routines. He is also fond of remembering that he did his best "to improve the style of official writing" (VIII: 135), which meant disregarding "old forms" and creating meaningful new ones. Under the aegis of the Post Office, Trollope describes himself as both "organization man" and "creative man".

The conclusion we can draw is that representing himself as a creative individual, rather than simply a producer, is indeed one of Trollope's priorities. Although his much-quoted statements on the business of writing and irreverent analogies between authors and shoemakers do stand out in the Autobiography, he is just as preoccupied with the codification of the right creative ethos for the literary field in which he operated. This field was imperfectly regulated, as Trollope knew all too well. The issue of ownership and control of one's own creations was a palpable concern for all British authors who feared they were losing money from the unregulated sale of their books in the vast North American market.

Trollope frames this controversial scenario in dualistic terms: on the one hand, the "book-selling leviathans" (XVII: 311), the corporate interests of a few, powerful American publishers; on the other, the unprotected interests of British authors and British publishers, victims alike of "American dishonesty" (XVII: 312). Whereas in the domestic market Trollope felt confident that the right business attitude coupled with a good dose of individual talent was likely to be rewarded in the end, the international market seemed to challenge his convictions. Thousands of American readers had easy access to his novels, but he was none the richer for that. He could have trebled his production of books, without receiving "one shilling" more (XVII: 313). In this context, the most problematic issue is the reproducibility of creative ideas: novels can be reissued in cheap American editions, sold to a diversified readership, disseminated widely and be entirely disconnected from the source that issued them originally. Trollope recounts in the Autobiography one telling anecdote about the potential threat to the author's individual identity posed by an open, unregulated market. On his way back from Australia across America, he intended to pay a visit to "the great polygamist of the Salt Lake City” (XIX: 350). After sending him a card, announcing this visit, Trollope was met with a surprisingly cold reception:

He received me in his doorway, not asking me to enter, and inquired whether I were not a miner. When I told him I was not a miner, he asked me whether I earned my bread [...] I told him that I did so by writing books. 'I am sure you're a miner,' said he. Then he turned upon his heels, went back into the house, and closed the door. I was properly punished, as I had been vain enough to conceive that he would have heard my name. (XIX: 350)

Narrated with much self-irony, this episode epitomizes the devaluation of the author's name and professional identity in the American scene. Paradoxically, in the market where Trollope's novels sell more copies, his name is meaningless: dissemination and 
lack of public recognition seem to go hand in hand. How does the Autobiography respond to this threat? Trollope falls back on the model of the artisan-producer and redefines the creative ethos in extreme, almost fastidious terms. The famous analogy between shoemaking and novel-writing occurs in the context of Trollope's discussion of international copyright, and it is there for a reason:

But the American readers are more numerous than the English, and taking them all through, are probably more wealthy. If I can get $£ 1000$ for a book here (exclusive of their market), I ought to be able to get as much there. If a man supply 600 customers with shoes in place of 300 , there is no question as to such a result. Why not, then, if I can supply 60,000 readers instead of 30,000?”. (XVII: 309)

This mundane comparison harks back to a simplified image of the market as an uncomplicated arena in which the alienating effects, experienced by authors in an international marketplace, are magically neutralized. ${ }^{14}$ The shoemaker gets paid his due and nothing interferes with the general principle that the individual who produces more earns more. In other words, the shoemaker analogy-often interpreted as an instance of Trollopian self-deprecation-reads like the wish-fulfilment fantasy of a mid-Victorian novelist who, at the zenith of his popularity, has to come to terms with his own anxieties about the uncontrolled and unprotected dissemination of his works in an open marketplace. The more aggressively American publishers "appropriate the goods of other people" (XVII: 311), and the more relentlessly they control the international market, the more persistently Trollope invokes a model of production based on soft control, on a form of self-management that aims at restoring a higher degree of control to the individual creator.

When Trollope suggests that writers like shoemakers should not stop in idle contemplation after their first pair of shoes is finished, he might be hinting at the advantages of mechanized production. But there is also a fantasy that this most prosaic comparison entails. This fantasy reverses the alienation and depersonalization of the unprotected author by projecting an image of the heroic artisan who needs no protection. This artisan carries on producing shoes and novels in splendid isolation, finding his work in itself rewarding: "I could be really happy only when I was at work-explains TrollopeI had now quite accustomed myself to begin a second pair as soon as the first was out of hand" (XVII: 324).

It is statements such as these that have induced critics to describe Trollope's method using the metaphor of the "novel-machine" (Kendrick). Yet, in the specific context in which these statements occur, the unfailing, mechanical producer is arguably more humanized than the nameless or depersonalized professional whose services are not adequately rewarded in an unregulated international market. The shoemaker is the symbol of an unproblematic model of pure market exchange, uncontaminated by the play of corporate interests and untroubled by anxieties as to the future value of his goods. Trollope uses this simplified idea of the market to counteract the more threatening and less pliable reality of the global marketplace in which the value of his novels was indeed a matter of contention.

Trollope's defensiveness about the ownership of words- "I have never printed as my own a word that has been written by others" (VI: 116) — can also be seen as a response 
to the sense of uncertainty and unease engendered by an unregulated marketplace in which creative ideas, reproduced in cheap formats and scattered over a wide space, are disconnected from their matrix. Having a large international readership is in itself not a bad thing. But if such dissemination implies a lack of recognition in economic terms, then it becomes a problem. Since for the narrator of the Autobiography market price is also an indication of cultural value, American dishonesty is indeed disturbing. It is cheapening in a most vulgar way: it depreciates creation by turning it into a mechanical reproduction process over which the author has virtually no control. So the Trollope who eloquently speaks in favour of an international copyright regulation is not just hankering after more profits. He is defending the quality of the service he provides to an international audience-a service that, to all practical purposes, is cheapened by not being remunerated in an appropriate way. In this case, the lack of profit is indeed a vulgarization of the act of creation, whereas Trollope's comparison between writers and shoemakers evokes a more transparent and civilized example of market exchange. His defensiveness about the ownership of words, characters and plots is another way of reasserting the authority of his own creative mind vis-à-vis American "leviathans" that, in a most ungentlemanly way, gain a competitive advantage by buying brains cheap.

\section{Conclusion}

Trollope's appeal to the language of trade serves the ideological function of repositioning the author who writes for the market as a free agent who is not subservient to the market. The figure of the literary tradesman depicted in this text is not one-sided, nor is this tradesman always perfectly at ease in the marketplace. His sense of comfort is constructed retrospectively by mobilizing the entrepreneurial rhetoric and, more conspicuously, by flaunting grand totals. These sums, however, are not simple, unproblematic quantifications. The narrator of the Autobiography constantly worries about the tension between aesthetic and economic value, between cultural and market price. To describe himself as a good negotiator and an efficient price maker is not enough. The price he demands has to be justified as a fair one in the dual market he supplies: the market where commodities are bought and sold and the market where creative ideas circulate.

If there is a fantasy that An Autobiography articulates, it is a fantasy many artists dream about: the joint maximization of cultural and economic value, the perfect combination of money and prestige. Some aspects of Trollope's theory of realism contribute to sustaining this fantasy. As a creator of memorable characters who change and grow into "real personages" over the course of many novels, Trollope becomes the generator of a cultural value ideally equal to the exchange value of the commodities he sold so profitably to the publishers. If the mid-Victorian critical establishment did not fully recognize the cultural value of those overabundant commodities, the Autobiography suggests how quantity and quality could be harmonized. Finally, the seemingly unflattering comparison between writers and shoemakers is not an expression of vulgar materialism. As a response to the dishonesty and predatory vulgarity of American publishers, Trollope's ideal shoemaker evokes a less degraded and more dignified 
image of the market in which the producer of shoes or novels gets his fair reward, enjoys what he does and exerts a higher degree of control over the process of market exchange. This is not vulgar materialism but honest idealism. The market may be a fact of life, but it takes a good dose of Trollopian castle-building to turn this reality into an arena where conflicting ideals find their equilibrium.

In Trollope's account the creative faculty is not up for sale. Only books are. This faculty is a valuable resource, a form of human capital that, wisely invested, leads to social advancement. It is the link between this kind of investment and social distinction that renders profit-making gratifying, or in Trollope's terms "sweet": "But though the money has been sweet, the respect, the friendships, and the mode of life that has been achieved, have been much sweeter" (IX: 168). The success stories and middle-class male romances of the Dick Whittington type Trollope might have had in mind when shaping his own narrative of success tended to eschew the pleasure of money-making. Trollope could afford to be more frank and open on this issue because he understood profits as a public recognition of the supplementary value of creative ideas. If this is

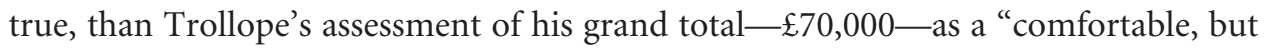
not splendid" result (XX: 365) insinuates the final doubt that his creative talent was not fully rewarded by the market. Perhaps his doubt was well-founded.

\section{Notes}

[1] See Macmillan's Magazine 44 (1883): 47-56, qtd. in Aguirre 569.

[2] Skilton (126-37) and Kendrick have both underlined the relevance of Trollope's theory of realism developed in the Autobiography. "For Trollope's traditional critics"-writes Kendrick- "his Autobiography has remained as banal as it was when it was published in 1883. But for the present study [...] this cliché-ridden book is the clearest, most comprehensive statement of the theory of realism that realism itself has ever produced" (3). Kendrik published his study in 1980. In recent years a number of critical essays have appeared that do not consider An Autobiography at all "banal". See Aguirre, Allan, Gilead and Miller.

[3] On the "entrapped successiveness" of much Victorian autobiographical writing see Davis (81-86). He concludes that "it is only in its breakdowns and its failures [...] that Victorian autobiography ironically succeeds" (94). Aguirre claims that the "order of his topics", in Trollope's Autobiography, seems "improvised an unpredictable" (5). Although this holds true, generally speaking, of many digressive sequences, there are some interesting connections between the theories Trollope expounds and the anecdotes he recounts especially in the first volume of An Autobiography.

[4] I have borrowed this expression from Shaw and Newey who use it in their analysis of John Clare's autobiography (3).

[5] David Skilton argues that the "Autobiography was completed in 1876 when [Trollope's] sales and reputation had declined drastically" (126).

[6] I draw here on Perkin's model of class "ideals". On the lack of symbolic prestige of the entrepreneurial ideal in Victorian and Edwardian culture see Weiner and McKendrick.

[7] On the rise of the professions see also Perkins and Robbins.

[8] When high-cultural or elitist norms are invoked, however, as in the "field of restricted production", high cultural value is associated with low economic value (Bourdieu 39). In Trollope's literary field, the division between "the field of restricted production, in which the producers produce for other producers, and the field of large-scale production, which is 
symbolically excluded and discredited" (Ibid.) was not as clear-cut as it became towards the end of the century.

[9] I allude here to Appadurai's idea that "economic objects circulate in different regimes of value in space and time" (4).

[10] This theory is further developed in chapter XII, where the emphasis however falls on the "established intimacy" between an author and his characters, rather than, as in chapter X, on the cumulative cultural value of "creations" that exceed the limits of one single text.

[11] On the mechanism of value-switching see Gregory; on the relationship between "commoditization" and "singularization" see Kopytoff.

[12] These are also some of the longest novels he ever wrote. The Small House at Allington totalled

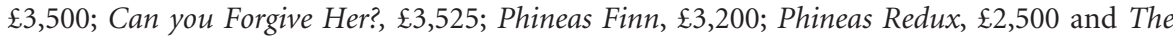
Prime Minister, $£ 2,500$.

[13] For a perceptive reading of Trollope's "addictive realism" see Crosby.

[14] Trollope uses the same analogy in chapter VII of the Autobiography where he discusses his "system of task-work". The point he makes is that neither shoemakers nor writers should wait for the "divine moment" of inspiration (VII: 121). The business of writing is just that, a business. Pseudo-romantic notions, therefore, are not useful. David Skilton suggests that the recurrent use of this analogy to reinforce the idea that creativity is just work might also be a polemical response to the accusation critics levelled at Trollope. The Saturday Review, for instance, had accused him of making a novel "just as he might make a pair of shoes" (qtd in Skilton 128). Sutherland claims that Trollope's deployment of this analogy, in both the letters and the Autobiography, reinforces "the conception of himself as a rapidly productive formula novelist" (150), making "the same article with small variations time and again" (Victorian Publishers 149).

\section{Works Cited}

Aguirre, Robert. "Cold Print: Professing Authorship in Anthony Trollope's An Autobiography." Biography 25.4 (2002): 569-92.

Allen, Peter. "Trollope to His Readers: The Unreliable Narrator of An Autobiography." Biography 19.1 (1996): 1-18.

Appadurai, Arjun. ed. The Social Life of Things. Commodities in Cultural Perspective, Cambridge: Cambridge UP, 1988.

Bodenheimer, Rosemarie. "Knowing and Telling in Dickens's Retrospects." Knowing the Past. Ed. S. Anger. Ithaca: Cornell UP, 2001. 215-233.

Bourdieu, Pierre. The Field of Cultural Production. Cambridge: Polity Press, 1993.

Crosby, Christina. “A Taste for More': Trollope's Addictive Realism." The New Economic Criticism. Ed. Martha Woodmansee and Mark Osteen. London: Routledge, 1999. 293-306.

Davis, Philip. "Why Do We Remember Forwards and Not Backwards?" Mortal Pages, Literary Lives. Eds. Vincent Newey and Philip Shaw. Aldershot: Scholar Press, 1996. 81-102.

Gilead, Sarah. "Trollope's Autobiography: The Strategies of Self-Production.” Modern Language Quarterly 47.3 (1986): 272-90.

Gregory, Chris. "Value Switching and the Commodity Free Zone." Gifts and Interests. Ed. Anton Vandevelde. Leuven: Peeters, 2000. 94-112.

Kendrick, Walter. The Novel-Machine. The Theory and Fiction of Anthony Trollope. Baltimore: The Johns Hopkins UP, 1980.

Kincaid, James. “Trollope's Fictional Autobiography.” Nineteenth-Century Fiction 37 (1982): $340-49$.

Kopytoff, Igor. "The Cultural Biography of Things: Commoditization as a Process." The Social Life of Things. Commodities in Cultural Perspective. Ed. A. Appadurai. Cambridge: Cambridge UP, 1986. 64-91. 
McKendrick, Neil. "Gentleman and Players' Revisited: The Gentlemanly Ideal, the Business Ideal and the Professional Ideal in English Literary Culture." Business Life and Public Policy. Ed. Neil McKendrick and R. B. Outwhite. Cambridge: Cambridge UP, 1986. 98-136.

Miller, Andrew. Novels Behind Glass: Commodity Culture and Victorian Narrative, Cambridge: Cambridge UP, 1995.

Newey, Vincent, and Philip Shaw. Eds. Mortal Pages, Literary Lives: Studies in Nineteenth-Century Autobiography. Aldershot: Scholar Press, 1996.

Perkin, Harold. The Origins of Modern English Society, 1780-1880. London: Routledge, 1969.

Pettitt, Clare. Patent Inventions. Intellectual Property and the Victorian Novel. Oxford: Oxford UP, 2004.

Robbins, Bruce. Secular Vocations: Intellectuals, Professionalism, Culture. London: Verso, 1993.

Rowse, A. L. "Trollope's Autobiography." Trollope Centenary Essays. Ed. John Halperin. New York: St. Martin's Press, 1982.

Searle, Geoffrey. Morality and the Market in Victorian Britain. Oxford: Clarendon, 1998.

Skilton, David. Anthony Trollope and His Contemporaries. Basingstoke: Macmillan, 1996.

Sutherland, John. Victorian Novelists and Publishers. Chicago: U of Chicago P, 1976. - Victorian Fiction: Writers, Publishers, Readers. London: Macmillan, 1985.

Throsby, David. Economics and Culture. Cambridge: Cambridge UP, 2001.

Trollope, Anthony. An Autobiography (1883). Oxford: Oxford UP, 1987.

Weedon, Alexis. Victorian Publishing. Aldershot: Ashgate, 2003.

Wiener, Martin. English Culture and the Decline of the Industrial Spirit. Harmondsworth: Penguin, 1985. 